\title{
Pratiques
}

Linguistique, littérature, didactique

183-184| 2019

oralité, littératie

\section{Raison graphique}

Jean-Marie Privat

\section{(2) OpenEdition}

Journals

Édition électronique

URL : http://journals.openedition.org/pratiques/6802

DOI : $10.4000 /$ pratiques. 6802

ISSN : 2425-2042

\section{Éditeur}

Centre de recherche sur les médiations (CREM)

Référence électronique

Jean-Marie Privat, «Raison graphique », Pratiques [En ligne], 183-184 | 2019, mis en ligne le 30

décembre 2019, consulté le 11 octobre 2020. URL : http://journals.openedition.org/pratiques/6802 ; DOI : https://doi.org/10.4000/pratiques.6802

Ce document a été généré automatiquement le 11 octobre 2020

(c) Tous droits réservés 


\title{
Raison graphique
}

\author{
Jean-Marie Privat
}

1 Cette notion est une traduction/adaptation française du titre de l'ouvrage de référence de J.Goody, The domestication of the savage mind. Dans La Raison graphique. La domestication de la pensée sauvage, l'anthropologue britannique développe l'idée que nos modes et habiletés de pensée ne sont pas indépendants des modes de communication. Ainsi l'écrit dispose le/du langage comme d'un objet sémiotique structuré par sa linéarité et sa spatialité. La mise en ligne - droite ou non - en tableau à plusieurs entrées et en colonnes - horizontales et verticales entrecroisées ou non - du langage produit des effets cognitifs spécifiques d'organisation et de compréhension du monde et de soi. Un dictionnaire et un index ou un schéma et une carte n'ont pas d'existence pratique en régime d'oralité. L'écrit met sous les yeux et comme à distance les discours y compris les nôtres les plus intimes - ; il tend ainsi à induire une forme de rationalité plus «froide» et plus propice à l'examen critique ou scientifique des données langagières. Mais dans le même temps il s'expose à laisser échapper une partie de la densité humaine et de la complexité mouvante du monde. C'est en un sens de cette déraison graphique que la littérature joue ou se joue. Voir aussi, J.-M. Privat (2018).

\section{BIBLIOGRAPHIE}

GOODY, J. (1977). The domestication of the savage mind. Cambridge/New York/

Melbourne : Cambridge University Press.

GOODY, J. (1978) [1977]. La Raison graphique. La domestication de la pensée sauvage. Trad. de l'anglais par J. Bazin \& A. Bensa. Paris : Éditions de Minuit. 
PRIVAT, J.-M. (2018). « Sur La Raison graphique. La domestication de la pensée sauvage de Jack Goody ». Questions de communication 33, p. 299-323. En ligne : https://journals.openedition.org/ questionsdecommunication/12581.

\section{AUTEUR}

\section{JEAN-MARIE PRIVAT}

Université de Lorraine, Crem, F-57000 Metz, France 